\title{
An unusual presentation of multiple haemangiomas of the liver
}

\author{
Niroshan Amarasiri ${ }^{1}, \mathbf{S}$ Lokuarachchi ${ }^{2}$ \\ ${ }^{l}$ Registrar paediatrics, ${ }^{2}$ Consultant paediatrician, Teaching Hospital, Karapitiya.
}

A 21 hour-old, term neonate with birth weight of $2.35 \mathrm{~kg}$ was admitted to the special care baby unit (SCBU) of the Teaching Hospital, Karapitiya due to severe pallor. She is a product of nonconsanguineous parents. Antenatal period was uneventful and the mother was not on any anticonvulsants or warfarin. Baby was delivered by vacuum extraction due to prolonged labour. There was no history of birth trauma or asphyxia. Vitamin K was given at birth. Around 2 hours of age she was found to be extremely pale and was transferred to SCBU. On admission, she was very pale but not icteric. She was active, afebrile and there were no signs of sepsis or congenital infections. There were no hemangiomas or capillary malformations over the skin. Rest of the examination was normal.

Her $\mathrm{Hb}$ concentration was $3.9 \mathrm{~g} / \mathrm{dL}$, WBC count was $9 \times 10^{9} / \mathrm{L}$ (neutrophils - 70\%, lymphocytes $28 \%$ ) and platelet count was $200 \times 10^{9} / \mathrm{L}$. Blood picture showed normochromic, normocytic red cells with many polychromatic cells and normoblasts. Leucocytes and platelets appeared normal. Reticulocyte count was 6\%. Maternal blood group was $\mathrm{B}^{+}$and the baby's blood group was $\mathrm{O}^{+}$. Unexpected antibodies were not detected. Serum bilirubin was within the normal range. Clotting profile including prothrombin time was normal. SGOT (61 u/L) and SGPT (74 $\mathrm{u} / \mathrm{L}$ ) were at the upper limit of the normal range.
On the day of admission a blood transfusion and an additional dose of vitamin $\mathrm{K} 1 \mathrm{mg}$ IM was given. Post-transfusion $\mathrm{Hb}$ was $12.1 \mathrm{~g} / \mathrm{dL}$. At forty-eight hours of age, the baby developed bleeding per rectum without any other bleeding manifestations.

Ultrasound scan of the abdomen showed a normal sized liver with multiple hyperechogenic foci within it. CT scan of the abdomen revealed multiple haemangiomas of the liver. There were no further episodes of bleeding. Child was sent home with a plan of close follow-up and to do a colonoscopy if the symptoms recur. Our clinical impression was multiple haemangiomas of the liver associated with haemangiomas of the gastrointestinal tract.

\section{Discussion}

Infantile haemangiomas are benign vascular neoplasms that have a characteristic clinical course marked by early proliferation and followed by spontaneous involution. Haemangiomas can occur in skin and extracutaneous sites including liver, gastrointestinal tract, larynx, central nervous system, pancreas, gallbladder, thymus and the spleen. Haemangioma are the commonest type of hepatic vascular tumours that present in infancy. It may occur as solitary lesions or as multiple 
lesions in the liver. It is commonly associated with cutaneous lesions and rarely with hemangiomas in the gut wall [1].

The commonest complication of hepatic haemangioma is congestive cardiac failure which needs intensive medical therapy [2]. Pressure on the stomach and duodenum by large pedunculated lesions may present with abdominal pain, nausea and vomiting. Compression of inferior vena cava may result in "Budd-chiari syndrome".

The "Diffuse neonatal haemangiomatosis" is a rare disorder that usually present in infancy and has a high mortality rate. They have haemangiomas which are calcified in the liver, bowel wall, spleen, and adrenal gland [3].

The infantile haemangiomas are asymptomatic and treated conservatively with watchful expectancy. The goals of pharmacotherapy are to reduce morbidity and to prevent complications. Oral and intralesional corticosteroids are effective at slowing growth and decreasing the size of proliferating haemangiomas. Interferon 2-a inhibits endothelial cell migration and specific growth factor. It can be used in lesions that are unresponsive to steroids. Laser surgery is beneficial in treating both proliferating and residual vessels of haemangiomas. When liver haemangiomas are complicated with cardiac failure, it can be treated with ligation of hepatic artery and prednisolone, digoxin, diuretics [4].

\section{References}

1. Boon LM, Burrows PE, Paltiel HJ, Lund DP, Ezekowitz RA, Folkman J, Mulliken JB. Hepatic vascular anomalies in infancy - a twenty seven year experience. Journal of Pediatrics 1996; 129(3): 34654.

2. Roebuck DJ. Hemangioendothelioma of the liver in infants. Journal of Pediatric Surgery 1995; 30(11): 1632.

3. Latifi HR, Siegel MJ. Diffuse neonatal hemangiomatosis; CT finding in an adult. Journal Computer Assisted Tomography 1992; 16(6): 971-3.

4. Davenport M, Hansen L, Heaton ND, Howard ER. Hemangioendothelioma of the liver in infants. Journal of Pediatric Surgery 1995; 30(1): 44-8. 